\title{
Онтогенетическая структура ценопопуляций некоторых редких видов растений Азербайджана
}

\author{
(С Г.О. Османова ${ }^{1}$, Н.П. Мехтиева ${ }^{2}$, Р.Ф.Абдыева ${ }^{2}$ \\ ${ }^{1}$ Марийский государственный университет, г. Йошкар-Ола, Россия \\ e-mail: gyosmanova@yandex.ru \\ ${ }^{2}$ Институт Ботаники Национальной Академии Наук Азербайджана, г. Баку, Азербайджан \\ e-mail:naiba_m@mail.ru
}

\begin{abstract}
Впервые с использованием популяционно-онтогенетического подхода в разных районах Азербайджана изучена онтогенетическая структура ценопопуляций редких видов растений разных жизненных форм (Rhus coriaria, Parrotia persica, Pyrus salicifolia, Ornithogalum ponticum, Ophrys caucasica). Рассчитаны демографические показатели, определены типы ценопопуляций по классификации «дельта-омега». Выявлено, что ценопопуляции всех изученных видов по возрастной структуре нормальные. Установлено, что сильное рекреационное воздействие губительно влияет на ценопопуляции Parrotia persica и Ornithogalum caucasica. Угроз для сокращения численности особей Rhus coriaria, Pyrus salicifolia и Ornithogalum ponticum нет, т.к. возобновление первых двух происходит как семенным, так и вегетативным способом, а последний вид хорошо размножается вегетативно.
\end{abstract}

Ключевые слова: Азербайджан, ценопопуляция, онтогенетическая структура, индекс возрастности, классификация ценопопуляций, Rhus coriaria, Parrotia persica, Pyrus salicifolia, Ornithogalum ponticum, Ophrys caucasica

Азербайджанская Республика расположена в юго-восточной части Европейского континента за Большим Кавказским хребтом на берегу Каспийского моря, граничит с Россией, Ираном. Турцией, Грузией и Арменией. Более половины территории Азербайджана занимают горы, относящиеся к системе Большого и Малого Кавказа. Вместе с Талышскими горами они охватывают Кура-Араксинскую низменность с севера, запада и юго-востока. Своеобразие рельефных и климатических особенностей страны создало в регионе благоприятные условия для развития богатой флоры. К сожалению, большинство представителей этой флоры нуждаются в охране.

Первое издание Красной книги Азербайджана, в которую было включено 140 видов высших растений вышло в 1989 г. (Kuliev, 1989). Обновленное и дополненное 2-е издание Красной книги опубликовано в 2013 г. (Ali-zade, 2013) и насчитывало уже 300 видов (266 видов высших растений, 13 видов лишайников, 1 вид мхов, 6 видов водорослей, 14 видов грибов). Во 2-м издании в отличие от 1-го была проведена оценка высших растений по категориям IUCN (2001). В новую Красную книгу вошли 90 видов из Красной книги 1-го издания и 41 вид из Красной книги CССР (Borodin et al., 1984). В нее вошли эндемичные виды, среди которых - эндемики Азербайджана (31 вид), эндемики Кавказа (69 видов), реликты (18), гирканские (5 видов).
Снижение глобального биоразнообразия привело к необходимости глубокого изучения механизмов устойчивости популяций растений, особенно редких. Этим и определена цель нашего исследования.

\section{Матери али методика}

Впервые для Азербайджана в Институте Ботаники НАН Азербайджана проводятся работы по изучению и прогнозированию состояния популяций редких видов (Kozyreva et al., 2010; Mekhtieva et al., 2015; Osmanova, Rustamov, 2016; Abdyeva et al., 2016; Dadasheva et al., 2016; Abdyeva et al., 2017; и др.).

Работа ведется на популяционном и ценотическом уровнях с применением классических методов морфологии, систематики, популяционной биологии и фитоценологии.

В данной работе, в качестве примера, нами приведены результаты изучения онтогенетической структуры и состояния ценопопуляций (ЦП) редких видов растений разных биоморф: сумаха дубильного (Rhus coriaria L.), парротии персидской (Parrotia persica (DC.) C.A.Mey.), груши иволистной (Pyrus salicifolia Pall.), птицемлечника понтийского (Ornithogalum ponticum Zahar) и офрис кавказской (Ophrys caucasica Woronow ex Grossh.).

Исследования проводили в 2015-2016 гг. в разных районах Азербайджана. Размеры площадок для древесных видов растений составили $20 \times 20$ м, для 
травянистых - $1 \times 1$ м. При определении онтогенетических состояний особей использовали концепцию дискретного описания онтогенеза Т.А. Работнова (Rabotnov, 1950) и А.А. Уранова (Uranov, 1975). Были рассчитаны индексы: возрастности (Uranov, 1975), восстановления и замещения (Zhukova, 1995), старения (Glotov, 1998) и эффективности (Zhivotovsky, 2001). Тип ЦП определяли по классификации «дельта-омега» Л.А. Животовского (Zhivotovsky, 2001).

\section{Р езультаты иих обсуждение}

Сумах дубильный (Сем. Сумаховые - Anacardiaceae) - небольшое дерево или кустарник, лекарственное. Растет на сухих склонах и опушках. Изучение онтогенетической структуры ЦП $R$. coriaria проводили в 4-х районах Азербайджана: Губинском (3 ЦП), Шабранском (2 ЦП), Сиязанском (2 ЦП) и Исмаиллинском (4 ЦП). С использованием классификации нормальных ЦП Л.А. Животовского (Zhivotovskii, $2001)$ нами определен тип ЦП $R$. coriaria и построены онтогенетические спектры (Рис. 1, 2).

Согласно классификации «дельта-омега» и значениям индексов возрастности и эффективности из изученных 11 ЦП R. coriaria 3 ЦП - молодые (Ша- бранский p-он, с. Тахтала и Исмаиллинский р-н вдоль дороги Исмаиллы-Габала), 3 ЦП - переходные (Губнский р-он, окр. с. Гедик, Исмаиллинский р-он, окр. с. Иснов и вдоль дороги Исмаиллы-Габала), 2 ЦП - зреющие (Губинский р-он, окр. с. Исновгышлаг; Шабранский р-он, с. Тахтала) и 2 ЦП - зрелые (Сиязанский р-он, окр. Галалты).

Значения индекса возрастности в этих ЦП варьирует от 0,262 до 0,668, а индекса эффективности - от 0,138 до 0,836. Для оценки процессов самоподдержания в ЦП $R$. coriaria нами рассчитаны индексы восстановления и замещения. Значения этих индексов варьируют от 0,44 до 38,75 , соответственно. В переходных ЦП значения данных показателей не столь высоки ( $\mathrm{I}_{\text {в }}$ - от 0,44 до 1,0; $\mathrm{I}_{3}$ - от 0,39 до 0,78). Это можно объяснить тем, что в данных ЦП не высока доля особей прегенеративного периода. Индекс старения во всех ЦП $R$. coriaria имеет невысокое значение и варьирует от 0,04 до 0,28.

Bce 11 ЦП R. coriaria нормальные: 2 ЦП (Губинский р-он, окр. Гедик и Исмаиллинский р-он, горный склон) являются полночленными, а остальные 9 ЦП - неполночленные. Например, в Сиязанском р-не обе ЦП $R$. coriaria неполночленные и преимущественно состоят из особей генеративного

\section{Шабранский p-он (Shabranskii District)}
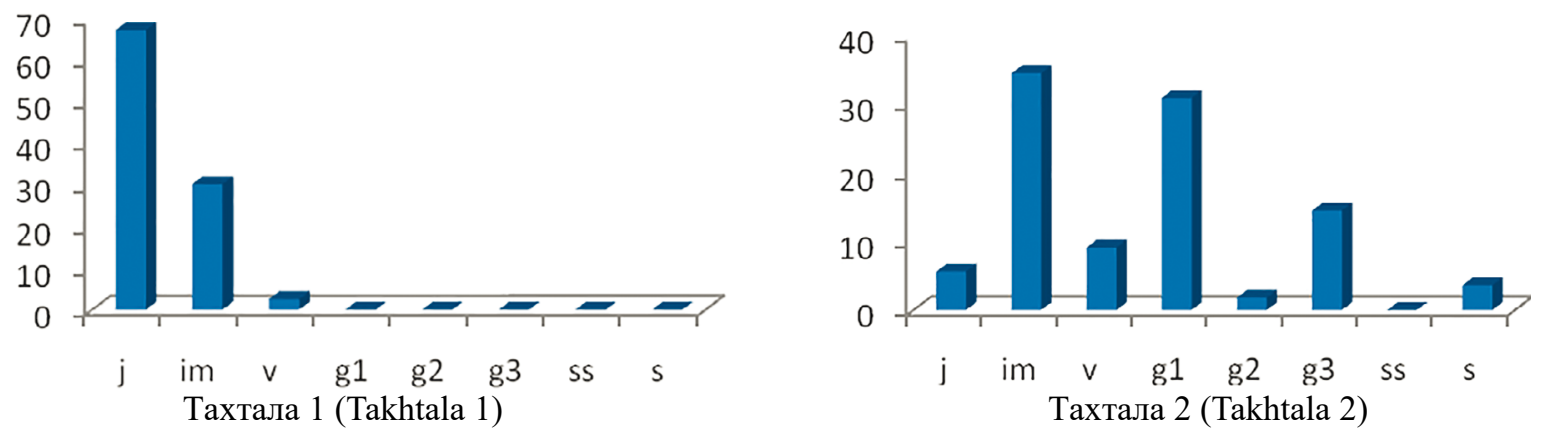

Сиязанский р-он (Siyazanskii District)

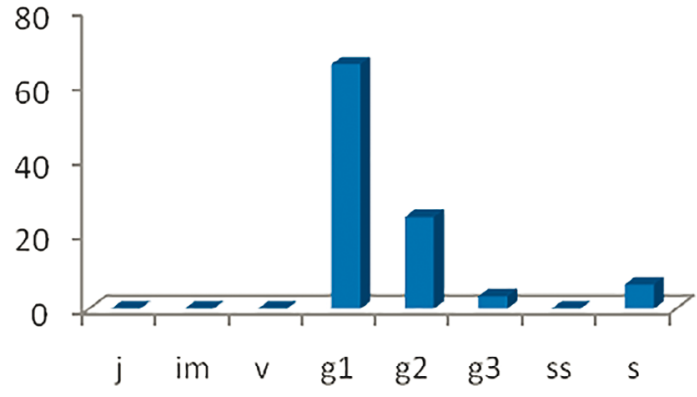

Галалты 1 (Galalty 1)

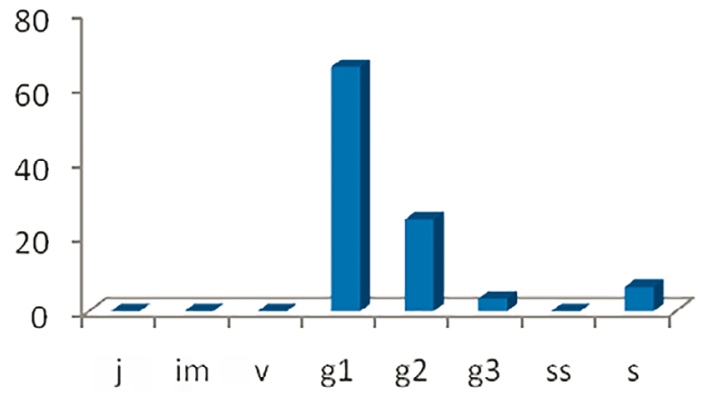

Галалты 2 (Galalty 2)

Рисунок 1. Спектры онтогенетических состояний Rhus coriaria (по оси ординат - доля особей в \%; по оси абсцисс онтогенетические состояния)

Figure 1. Spectra of ontogenetic states of Rhus coriaria (along the ordinate axis - the proportion of individuals in \%, along the abscissa axis - ontogenetic states) 
периода, поэтому эти ЦП согласно значениям индексов возрастности $(0,3876 ; 0,366)$ и эффективности $(0,7919 ; 0,0748)$ охарактеризованы нами как зрелые. Онтогенетические спектры преимущественно одновершинные с максимумом на особях генеративного периода.

Парротия персидская (железное дерево) - листопадное дерево, представитель сем. Гамамелисовые (Hamamelidaceae). Изучение онтогенетической структуры ЦП P. persica проводили в Ленкораньском, Астаринском и Массалинском р-ах. Все ЦП данного вида нормальные, но неполночленные из-за отсутствия особей $P$. persica ювенильного состояния.
Согласно значениям индексов возрастности и эффективности ЦП P. persica в Ленкораньском и Астаринском р-ах определены нами как старые (Рис. 3).

Подтверждением этому являются несколько высокие значения индекса старения $(0,29$ и 0,32$)$. Следует отметить, что, несмотря на присутствие в этих ЦП особей прегенеративного периода (im и v) значения индексов восстановления $(0,28$ и 0,39$)$ и замещения $(0,18$ и 0,24$)$ низкие, что свидетельствует о слабом самоподдержании. ЦП $P$. persica в Массалинском р-не была переходной $(\Delta=0,487$; $\omega=0,628)$. Индекс старения по сравнению с ЦП P. persica в Ленкоранском и Астаринском p-ах

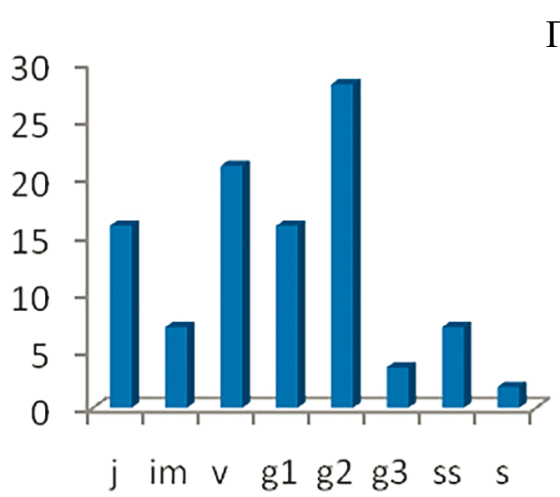

Гедик (Gedik)

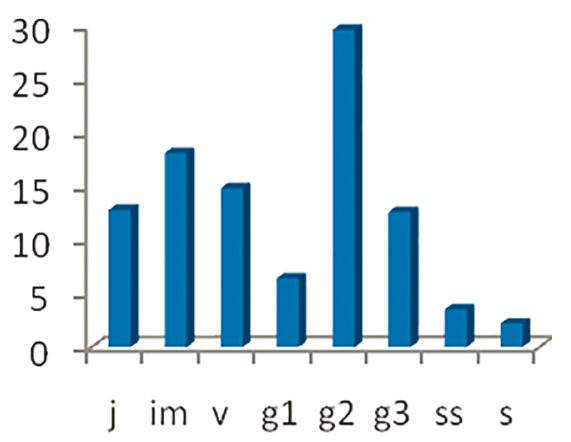

Галалты 1 (Galalty 1)
Губинский p-он (Gubinskii District)

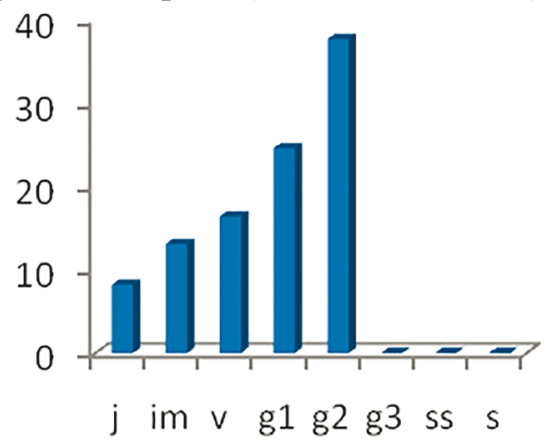

Исновгышлаг (Isnovgyshlak)

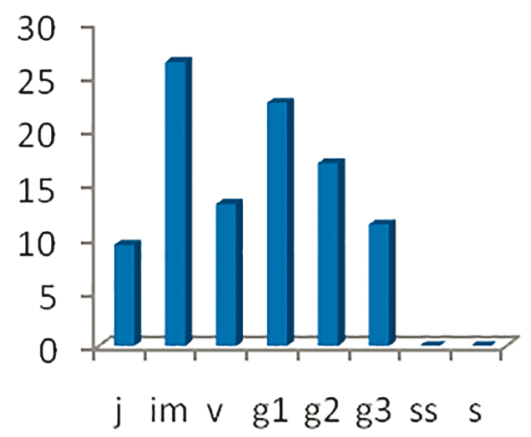

Иснов (Isnov)

Исмаилинский p-он (Ismailinskii District)

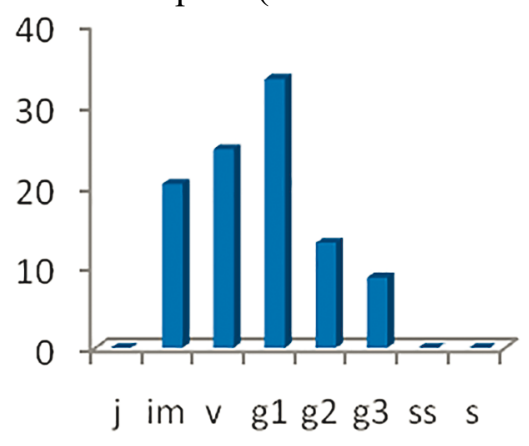

Галалты 2 (Galalty 2)

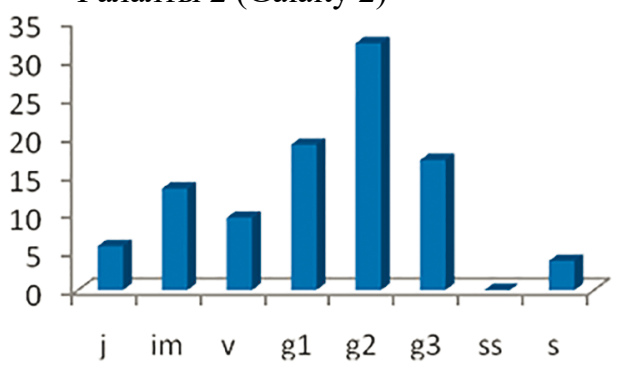

Галалты 4 (Galalty 4)

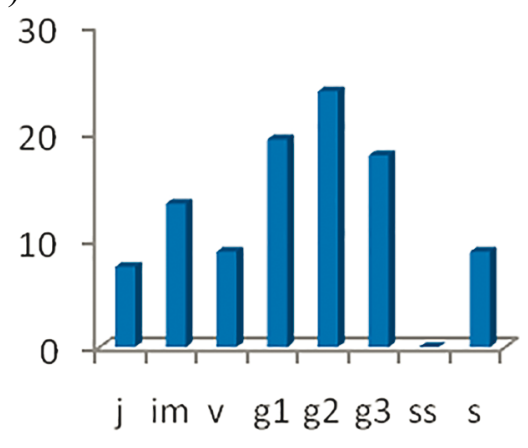

Галалты 3 (Galalty 3)

Рисунок 2. Спектры онтогенетических состояний Rhus coriaria (обозначения см. на рис. 1)

Figure 2. Spectra of ontogenetic states of Rhus coriaria (see the notation in Figure 1) 


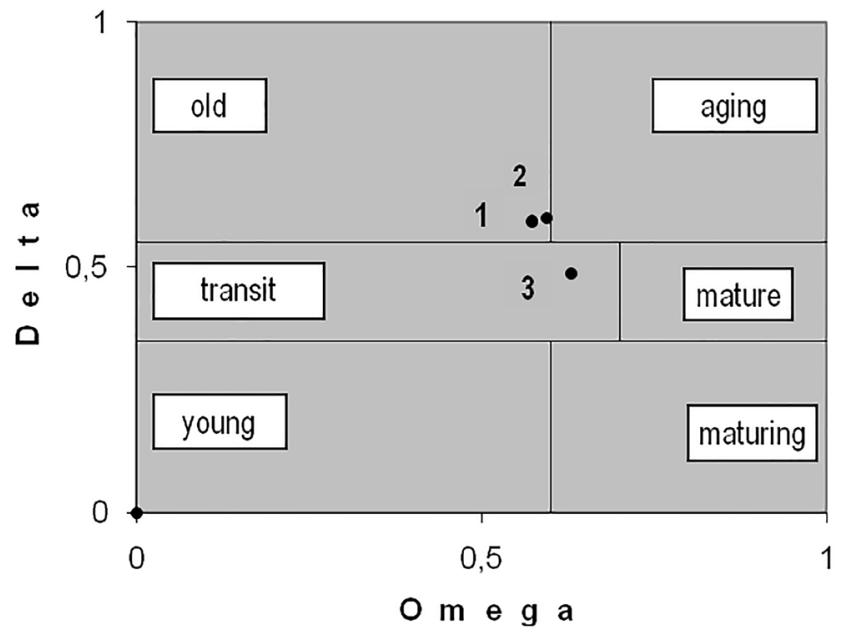

Рисунок 3. Распределение ценопопуляций Parrotia persi$c a$ в системе координат «дельта-омега» в разных районах (1 - Ленкоранский; 2 - Астаринский; 3 - Масаллинский)

Figure 3. Distribution of the cenopopulations of Parrotia persica in the "delta-omega" coordinate system in different districts (1 - Lenkoranskii, 2 - Astarinskii, 3 - Masallinskii)

имеет не высокое значение $(0,19)$, хотя значения индексов восстановления и замещения несколько высокие. Во всех изученных ЦП Р. persica нами обнаружены отмершие особи.

Груша иволистная (сем. Розовые - Rosaceae) листопадное дерево, иногда встречаются кустарниковые формы, произрастает на сухих предгорьях. Онтогенетическую структуру ЦП $P$. salicifolia изучали в Губинском р-не. Данный вид не образует зарослей, чаще встречается единично или образует малочисленные группы. ЦП P. salicifolia согласно классификации «дельта-омега» была охарактеризована как зреющая $(\Delta=0,719 ; \omega=0,291)$. Несмотря на присутствие в ЦП генеративных особей индекс восстановления имеет низкое значение. Возобновление данного вида происходит как семенным, так и вегетативным способом. В последнем случае за счет укоренения полегающих побегов кроны. Угроз для этого вида нет.

Птицемлечник понтийский (сем. Гиацинтовые - Hyacinthaceae) - многолетнее луковичное травянистое растение. Анализ онтогенетической структуры ЦП $O$. ponticum показал, что данный вид образует заросли с большим числом цветущих особей (на момент исследования) объем выборки варьировал от 16 до 348 особей. Плотность особей O. ponticum на $1 \mathrm{~m}^{2}$ колеблется от 46 до 63 . Во время исследования в ЦП были только цветущие молодые генеративные растения. По-видимому, это связано с поздними сроками проведения работ. И лишь в Хызынском и Губинском р-х в ЦП были отмечены единичные особи $O$. ponticum, находящиеся в im и v онтогенетических состояниях. Поэтому рассчитать демографические показатели не представлялось возможным.

Офрис кавказская (сем. Орхидные - Orchidaсеае) - многолетнее травянистое растение. По И.Г. Серебрякову (Serebryakov, 1962) O. caucasica можно отнести к травянистым многолетникам с корневыми клубнями, по И.В. Татаренко (Таtarenko, 1996) - к растениям со стеблекорневыми тубероидами. Офрис кавказская встречается на территории Азербайджана спорадически и очень редко. Зарослей не образует. В Сиязанском и Губинском р-х было обнаружено по одной ЦП. Объем выборки в ЦП составил 15 и 30 особей соответственно. В обеих ЦП были отмечены особи прегенеративного и генеративного периодов. В Сиязанском р-не (Бешбармаг) ЦП O. caucasica была зреющая $(\Delta=0,719 ; \omega=0,291)$, а Губинском (Гедик) - зрелая $(\Delta=0,352 ; \omega=0,808)$. Индекс восстановления имеет низкие значения $(0,2$ и 0,4$)$. Возобновление данного вида преимущественно происходит вегетативно за счет клубней.

\section{В ы в о д ы}

Применение классических подходов популяционной экологии и демографии растений для изучения поведения особей и популяций растений, особенно редких, определение их демографических параметров позволяют выявить механизмы функционирования биосистем разных иерархических уровней и предложить меры для их сохранения и восстановления: расширить границы заповедников и национальных парков с включением в их состав сопредельных территорий; создание новых ООПТ на ключевых, с точки зрения сохранения вида, территориях; организация постоянного контроля за состоянием популяций $R h$. coriaria, P. persica и $O$. caucasica; интродуцировать O. caucasica в ботанических садах Азербайджана с целью сохранения генофонда; плановое ведение хозяйственных мероприятий в местах произрастания популяций исследуемых видов; ограничить чрезмерную пастбищную нагрузку и запретить бессистемный выпас скота, а со стороны экологических служб - обеспечить контроль за деятельностью органов местного самоуправления. 


\section{С пи сок литературы}

[Abdyeva] Абдыева Р.Т., Османова Г.О., Мехтиева Н.П., Дадашева А.Г., Али-заде В.М. 2016. Онтогенетическая структура и оценка состояния ценопопуляций редкого вида Азербайджана Ophrys caucasica Woronow ex Grossh. В сб.: Биологическое разнообразие. Интродукция растений: Матер. шестой Международ. науч. конф. Санкт-Петербург. C. 303-305.

[Abdyeva] Абдыева Р.Т., Мехтиева Н.П., Османова Г.О. 2017. Влияние антропогенных факторов на состояние ценопопуляций Rhus coriaria L. B сб.: Влияние климатических изменений на биоразнообразие растений: матер. Международ. науч. конф. Баку. С. 248-251.

[Ali-zade] Али-заде В.М. (ред.). 2013. Красная книга Азербайджанской Республики (редкие и исчезающие виды растений и грибов). Баку. 665 с. (на азерб. яз.).

[Borodin] Бородин А.М., Банников А.Г., Соколов В.Е. и др. (ред.). 1984. Красная книга СССР: Редкие и находящиеся под угрозой исчезновения виды животных и растений. Том 1. 2-е изд. М. 392 с.

[Dadasheva] Дадашева А.Г., Османова Г.О., Ализаде В.М., Мехтиева Н.П., Абдыева Р.Т. 2016. Онтогенетическая структура и состояние ценопопуляций некоторых редких и эндемичных видов Азербайджана. В сб.: Актуальные проблемы биологии, экологии и химии: материалы научнопрактической конференции. Йошкар-Ола. C. $158-161$.

[Glotov] Глотов Н.В. 1998. Об оценке параметров возрастной структуры популяций растений. В кн.: Жизнь популяций в гетерогенной среде. Ч. 1. Йошкар-Ола. С. 146-149.

IUCN Red List Categories and Criteria: Version 3.1. 2001 IUCN Species Survival Commission. IUCN, Gland, Switzerland and Cambridge. $31 \mathrm{p}$.

[Kozyreva] Козырева С.В., Османова Г.О., Сеидова Л.Р., Али-заде В.М. 2010. Состояние ценопопуляций некоторых редких видов растений. В сб.: Регионы в условиях неустойчивого развития: матер. Международ. науч.-практ. конф. Кострома. С. $142-146$.

[Kuliev] Кулиев С. (ред.). 1989. Красная Книга Азербайджанской ССР. Баку. 544 с.

[Mekhtieva] Мехтиева Н.П., Абдыева Р.Т., Османова Г.О., Али-заде В.М. 2015. Онтогенетическая структура и оценка состояния ценопопуляций редкого эндемичного вида Iris acutiloba C.A. Меу. В сб.: Экологическая цивилизация, устойчивое развитие, окружающая среда: труды Азербайджанского Национального комитета «Человек и Биосфера» (МаB, Юнеско). Т. 10. Баку. С. 109-118.

[Osmanova, Rustamov] Османова Г.О., Рустамов Г.К. 2016. Онтогенетическая структура ценопопуляции астранции наибольшей (Astrantia maxima Pall.). В сб.: Наука, образование, общество: тенденции и перспективы: матер. Международ. науч.-практич. конф. М. №. 2-1 (5). С. 21-22.

[Rabotnov] Работнов T.A. 1950. Жизненный цикл многолетних травянистых растений в луговых ценозах. Тр. БИН АН СССР. Сер. III. Геоботаника. № 6. С. 23-26.

[Serebryakov] Серебряков И.Г. 1962. Экологическая морфология растений. Жизненные формы покрытосеменных и хвойных. М. С. 5-10.

[Tatarenko] Татаренко И.В. 1996. Орхидные России: жизненные формы, биология, вопросы охраны. M. 207 c.

[Uranov] Уранов А.А. 1975. Возрастной спектр фитоценопопуляций как функция времени и энергетических волновых процессов. Биол. науки. № 2. С. 7-34.

[Zhivotovskii] Животовский Л.А. 2001. Онтогенетические состояния, эффективная плотность и классификация популяций растений. Экология. № 1. С. 3-7.

[Zhukova] Жукова Л.А. 1995. Популяционная жизнь луговых растений. Йошкар-Ола. 224 с. 


\title{
Ontogenetic structure of cenopopulations of some rare plant in Azerbaijan
}

\author{
(C) G.O. Osmanova ${ }^{1}$, N.P Mehdiyeva ${ }^{2}$, R.F. Abdieva ${ }^{2}$ \\ ${ }^{1}$ Mari State University, Yoshkar-Ola, Russia \\ e-mail: gyosmanova@yandex.ru \\ ${ }^{2}$ Institute of Botany of the National Academy of Sciences of Azerbaijan, Baku, Azerbaydzhan \\ e-mail:naiba_m@mail.ru
}

\begin{abstract}
The ontogenetic structure of cenopopulations of rare plant species of different life forms (Rhus coriaria, Parrotia persica, Pyrus salicifolia, Ornithogalum ponticum, Ophrys caucasica) was studied for the first time using the population-ontogenetic approach in different regions of Azerbaijan. Demographic indicators are calculated, types of cenopopulations according to the delta-omega classification are determined. It was revealed that the cenopopulations of all studied species are normal by the age structure. It has been established that a strong recreational effect is detrimental to the cenopopulation of Parrotia persica and Ornithogalum caucasica. Threats to reduce the number of individuals Rhus coriaria, Pyrus salicifolia and Ornithogalum ponticum are not present, because the renewal of the first two occurs both in the seed and vegetative manner, and the last one propagates well vegetatively.
\end{abstract}

Keywords: Azerbaijan, cenopopulation, ontogenetic structure, index, classification, Rhus coriaria, Parrotia persica, Pyrus salicifolia, Ornithogalum ponticum, Ophrys caucasica

\section{Re f e r e n c es}

Abdyeva R.T., Osmanova G.O., Mekhtieva N.P., Dadasheva A.G., Ali-zade V.M. 2016. Ontogeneticheskaya struktura i otsenka sostoyaniya tsenopopulyatsii redkogo vida Azerbaidzhana Ophrys caucasica Woronow ex Grossh. [Ontogenetic structure and assessment of the condition of cenopopulations of a rare species of Azerbaijan Ophrys caucasica Woronow ex Grossh.]. In: Biologicheskoye raznoobraziye. Introduktsiya rastenii: Materialy shestoi Mezhdunarodnoi nauchnoi konferentsii [Biological diversity. Introduction of plants: Proceedings of the Sixth International Scientific Conference]. Saint-Pertersburg. 303-305 pp. (In Russ.)

Abdyeva R.T., Mekhtieva N.P., Osmanova G.O. 2017. Vliyaniye antropogennykh faktorov na sostoyaniye tsenopopulyatsii Rhus coriaria L. Rhus coriaria L. [Influence of anthropogenic factors on the condition of coenopopulations of Rhus coriaria L.]. In: Vliyaniye klimaticheskikh izmenenii na bioraznoobraziye rastenii: Materialy Mezhdunarodnoi naucchnoi konferentsii [The impact of climate change on plant biodiversity: Proceedings of the International Scientific Conference]. Baku. 248-251 pp. (In Russ.)

Ali-zade V.M. (ed.). 2013. Krasnaya Kniga Azerbaidzhanskoi Respubliki (redkiye $i$ ischezayushchiye vidy rastenii $i$ gribov) [The Red Book of the Republic of Azerbaijan (rare and endangered species of plants and fungi)] Baku. 665 pp. (In Aserb.)

Borodin A.M., Bannikov A.G., Sokolov V.E. et al. (ed.). 1984. Krasnaya Kniga SSSR: Redkiye i nakhodyashchiecya pod ugrozoi ischeznoveniya vidy zhivotnykh $i$ rastenii [Red Data Book of the USSR: Rare and Endangered Species of Animals and Plants]. Vol 1. Second edetion. M. 392 pp. (In Russ.)
Dadasheva A.G., Osmanova G.O., Ali-zade V.M., Mekhtieva N.P., Abdyeva R.T. 2016. Ontogeneticheskaya struktura i sostoyaniye tsenopopulyatsii nekotorykh redkikh i endemichnykh vidov Azerbaidzhana [Ontogenetic structure and condition of cenopopulations of some rare and endemic species of Azerbaijan]. In: $A k$ tualnyye problem biologii, ekologii i khimii: materialy nauchno-prakticheskoi konferentsii [Actual problems of biology, ecology and chemistry: materials of the scientific-practical conference]. Yoshkar-Ola. 158-161 pp. (In Russ.)

Glotov N.V. 1998. Ob otsenke parametrov vozrastnoi struktury populyatsii rastenii [On the evaluation of the parameters of the age structure of plant populations]. In: Zhizn populyatsii v geterogennoi srede [The life of populations in a heterogeneous environment]. Part 1. Yoshkar-Ola. 146-149 pp. (In Russ.)

IUCN Red List Categories and Criteria: Version 3.1. 2001. IUCN Species Survival Commission. IUCN, Gland, Switzerland and Cambridge. $31 \mathrm{p}$.

Kozyreva S.V., Osmanova G.O., Seidova L.R., Ali-zade V.M. 2010. Sostoyaniye tsenopopulyatsii nekotorykh redkikh vidov rastenii [The condition of cenopopulations of some rare plant species]. In: Regiony $v$ usloviyakh neustoichivogo razvitiya: Materialy Mezhdunarodnoi nauchno-prakticheskoi konferentsii [Regions in conditions of unsustainable development: Proceedings of the International Scientific and Practical Conference]. Kostroma. 142-146 pp. (In Russ.)

Kuliev S. (ed.). 1989. Krasnaya Kniga Azerbaidzhanskoi SSR [Red Book of the Azerbaijan SSR]. Baku. 544 pp. (In Russ.) 
Mekhtieva N.P., Abdyeva R.T., Osmanova G.O., Ali-zade V.M. 2015. Ontogeneticheskaya struktura i otsenka sostoyaniya tsenopopulyatsii redkogo endemichnogo vida Iris acutiloba C.A. Mey [Ontogenetic structure and assessment of the condition of cenopopulations of a rare endemic species Iris acutiloba C.A. Mey]. In: Ekologicheskaya tsivilizatsiya, ustoichivoye razvitiye, okruzhayushchaya sred: Trudy Azerbaidzhanskogo Natsionalnogo Komiteta "Chelovek $i$ biosfera" (MaB, Yunesko) [Ecological civilization, sustainable development, environment: Proceedings of the Azerbaijan National Committee "Man and the Biosphere" (MaB, Unesco).]. Vol. 10. Baku. 109-118 pp. (In Russ.)

Osmanova G.O., Rustamov G.K. 2016. Ontogeneticheskaya struktura tsenopopulyatsii astrantsii naibolshei (Astrantia maxima Pall.) [The ontogenetic structure of the cenopopulation of astrastia greatest (Astrantia maxima Pall.).]. In: Nauka, obrazovaniye, obshchestvo: tendentsii i perspektivy: Materialy Mezhdunarodnoi nauchno-prakticheskoi konferentsii [Science, Education, Society: Trends and Perspectives: Proceedings of the International Scientific and Practical Conference]. Moscow. Vol. 2-1 (5). 21-22 pp. (In Russ.)

Rabotnov T.A. 1950. Zhiznennyi tsikl mnogoletnikh travyanistykh rastenii v lugovykh tsenozakh [The life cycle of perennial herbaceous plants in meadow cenoses]. Trudy BIN AN SSSR. Ser. III. Geobotanika [Trudy BIN AS of the USSR. Ser. III. Geobotany]. 6: 23-26. (In Russ.)
Serebryakov I.G. 1962. Ekologicheskaya morfologiya rastenii. Zhiznennyye formy pokrytosemennykh $i$ khvoinykh [Ecological morphology of plants. Life forms of angiosperms and conifers]. Moscow. 5-10 pp. (In Russ.)

Tatarenko I.V. 1996. Orkhidnyye Rossii: zhiznennyye formy, biologiya, voprosy okhrany [Orchids of Russia: life forms, biology, protection issues]. Moscow. 207 pp. (In Russ.)

Uranov A.A. 1975. Vozrastnoi spektr fitotsenopopulyatsii kak funktsiya vremeni i energeticheskikh volnovykh protsessov [Age spectrum of phytocenopopulations as a function of time and energy wave processes]. Biologicheskiye nauki [Biological Sciences]. 2: 7-34. (In Russ.)

Zhivotovsky L.A. 2001. Ontogeneticheskiye sostoyaniya, effektivnaya plotnost i klassifikatsiya populyatsii rastenii [Ontogenetic states, effective density and classification of plant populations]. Ekologiya [Russian Journal of Ecology]. 1: 3-7. (In Russ.)

Zhukova L.A. 1995. Populyatsionnaya zhizn lugovykh rastenii [Population life of meadow plants]. Yoshkar-Ola. 224 pp. (In Russ.) 